\title{
Calibrating CII RT283's Modularization Critical Success Factor Accomplishments
}

\author{
Jin Ouk Choi ${ }^{1 *}$, James T. O'connor ${ }^{2}$, Young Hoon $\mathrm{Kwak}^{3}$, and Rajarshi Ghimire ${ }^{4}$ \\ ${ }^{1}$ Assistant Professor, Department of Civil and Environmental Engineering and Construction, \\ University of Nevada, Las Vegas \\ ${ }^{2}$ C. T. Wells Professor of Project Management, Dept. of Civil, Architectural and Environmental \\ Engineering, University of Texas at Austin \\ ${ }^{3}$ Associate Professor, Department of Decision Sciences, The George Washington University \\ ${ }^{4}$ Graduate Student, Department of Civil and Environmental Engineering and Construction, \\ University of Nevada, Las Vegas \\ *Corresponding author's e-mail: jinouk.choi@unlv.edu
}

\begin{abstract}
Modularization is a well-known construction technique where sections of the job are moved from on-site to a fabrication shop. Previously, the researchers identified the 21 most influential Critical Success Factors (CSFs) for successful modularization and quantified the degree of each CSF's accomplishment by conducting a survey with 19 subject matter experts, and a case study with three modular projects. Through this methodology, the findings relied on the experience of experts. However, still missing from the understanding of modularization CSFs is a validation of the current degree of each CSF's accomplishment by examining actual modular projects using a sufficient number of samples. This paper presents a comparison of CSF accomplishment degree between 25 actual sample projects (project based) and the industry experts' survey results (experience-based estimation). The study results indicate that the industry experts made a good estimation of the current occurrence degree of each CSF. The study did identify, however, three significantly overestimated CSFs and three underestimated CSFs. The three most overestimated CSFs are Owner-Furnished/Long Lead Equipment Specification, Cost Savings Recognition, and O\&M Provisions. The three most underestimated CSFs are Contractor Experience, Management of Execution Risks, and Transport Delay Avoidance. This study will help the industry to 1) better understand modularization CSFs and their accomplishment statuses; 2) achieve higher modular project performance by accomplishing the CSFs.
\end{abstract}

\section{KEYWORDS}

Modularization; Critical Success Factors; Industry Status; Prefabrication; Preassembly; Modular Construction; Offsite Construction (PPMOF)

\section{INTRODUCTION}

Modularization is a well-known construction technique where sections of the job are moved from on-site to a fabrication shop. This technique can improve the efficiency and productivity of the construction industry. Since its introduction, the value and benefits of modularization have been widely recognized. These include lower capital costs, improved schedule performance, increased 
productivity, higher overall quality, increased safety performance, reduced waste, and better environmental performance. However, the industry continues to struggle to achieve high levels of modularization. In recent years, the rapid development of the modularization technique has resulted in its re-emergence.

Previous studies have explored current trends and advantages in modularization, as well as some of the barriers to its application. However, few studies have sought to identify the success factors of modularization or the practices of expert modularization practitioners. To help clear up such issues, the Construction Industry Institute (CII) Research Team (RT) 283 identified the 21 most influential Critical Success Factors (CSFs) for successful modularization, and quantified the degree of each CSF's accomplishment by conducting a survey with 19 subject matter experts and a case study with three modular projects (CII 2012). The findings relied on the experience of experts. However, the researchers identified a lack of understanding of modularization CSFs and their accomplishment statuses. To better understand modularization CSFs, a validation of the current degree of each CSF's accomplishment, by examining actual modular projects using a sufficient number of samples, is needed.

\section{LITERATURE REVIEW}

The application of modularization decreases the overall cost and duration of the project whereas increases productivity, quality and safety. However, initial planning and engineering cost is more in this approach than the conventional stick-built approach. Over the years, numerous research studies have been carried out towards increasing the application of modularization in the construction industry. Such opportunities and barriers in the implementation of modularization instigated the researchers to identify decision-making factors and critical success factors required for its effective implementation (Azhar et al. 2012, CII 2012, O'Connor et al. 2014). Out of 72 potential success factors for modularization, the CII RT 283 identified the 21 most influential CSFs, which were ranked based on a survey (CII 2012). The study identified that Module Envelope Limitations, Alignment on Drivers, Owner's Planning Resources \& Processes, Timely Design Freeze and Early Completion Recognition were top five critical success factors. This literature review was organized by the top five CSFs.

Unlike the stick-built method, early planning and resources with a decision system are required for modular methods (Azhar et al. 2012, Hwang et al. 2018, O'Connor et al. 2014). Early planning results in timely completion of the project. Thus, it is necessary to plan for modularization in the front end of the project, mainly for ordering the long lead items. The scopes of all modules should be clearly defined in the front-end planning of a project (Alwisy et al. 2018, O'Connor et al. 2014, Sedaghat. 2016). Long lead or owner furnished equipment should be available on time, so that there is no adverse effect on schedule (O'Connor et al. 2014, Peltokorpi et al. 2018). Therefore, the suppliers must be timely identified and the required materials should be ordered with detail specification to ensure timely supply of materials at the fabrication yard or construction site (O'Connor et al. 2014, Shi et al. 2018). While stick built has the option of adding new specifications and changes, doing the same in a modularization approach will be expensive. For successful implementation of modularization as planned, timely design freeze is necessary for avoiding cost overrun ( $\mathrm{Li}$ et al. 2018, O’Connor et al. 2014). The stakeholders should determine an optimum proportion of modularization resulting in maximum savings. It is also important to 
address the operations and maintenance needs of the project while designing the modules (O'Connor et al. 2014). Meanwhile, the industry should recognize the opportunity for early completion of projects due to the application of modularization (O’Connor et al. 2014).

Module envelope limitation and alignment on drivers are crucial for the success of modularization. The transportation infrastructure capacity available between the fabrication shop and job site influences the size of the module (Azhar et al. 2012). Therefore, high consideration is required for transportation and logistics in the module envelope definition (Alwisy et al. 2018, Hwang et al. 2018, O'Connor et al. 2014, Salama et al. 2017, Sedaghat. 2016, Shahtaheri et al. 2017). In some cases, it is required to upgrade the transportation infrastructure ahead of time to avoid delays (O'Connor et al. 2014). Shi et al. (2018) discussed the contractor and supplier relationship detailing the vertical, horizontal, and lateral connections among the stakeholders. It is imperative that, in order to remove probable resistance from the owner in future, the contractor, supplier, and owner should be aligned early (Hwang et al. 2018, Molavi \& Barral, 2016, Pan et al. 2007, Peltokorpi et al. 2018 Shahtaheri et al. 2017,).

Further, contractor experience and leadership is paramount for the application of modularization and contractors should be recognized for cost benefit due to early completion. Contractor experience and leadership is required for effective and successful modularization. Therefore, selection of contractors based on their previous experience in modular projects is necessary (Li et al. 2018, O'Connor et al. 2014). The savings resulting from modularization should be considered during the cost-benefit analysis (O'Connor et al. 2014). Additionally, the module fabricators should have a larger fabrication yard with highly skilled manpower and enough machinery and equipment. Similarly, heavy lifting equipment and accessories, like cranes, should be available at construction site (O'Connor et al. 2014). The owner should be on good moral and financial ground to avoid delays on finance matters, commercial contracts, and technical scope (O'Connor et al. 2014).

In summary, Module Envelope Limitation, Alignment of Drives, Owner's Planning \& Resources, and Timely Design Freeze were discussed multiple times by researchers. Transportation and limitations induced by it, early planning, understanding of stakeholders, minimum resistance from owners, and minimum to no change on design are factors that impact the success of a modular project. CII (2012) RT283 first examined how often CSFs actually occur or are accomplished on projects. They surveyed about 20 industry experts to quantify the current degree of occurrence of each CSF. Due to this methodology, the findings relied on the experience of experts. However, still missing from the understanding of modularization CSFs is a validation of the current degree of each CSF's accomplishment by examining actual modular projects using a sufficient number of samples. This research made a commitment to fill the gap in the above literature in order to help industrial project stakeholders, from owners to fabricators and designers, as well as Engineering, Procurement, and Construction (EPC) contractors, to understand industrial modularization and MOD CSFs, and motivate them to achieve better project performance.

\section{Research Objectives}

The goal of this study is to shed light on modularization CSFs and to ascertain the status of their accomplishments. The study objectives are: 1) to examine the actual modular projects' 
accomplishments of the CSFs; 2) to compare modularization CSF accomplishment degree between 25 actual sample projects (project based), and the industry experts' survey results (experiencebased estimation); and 3) to validate the modularization CSFs.

This study primarily focuses the accomplishment of CSFs in (heavy and light) industrial projects in the upstream, downstream, midstream, and manufacturing sectors.

\section{METHODS}

To accomplish the research goal, the researchers first adopted the $21 \mathrm{CSFs}$ identified the CII research team 283 (O'Connor et al. 2014). Those 21 CSFs are:

1. Module Envelope Limitations

2. Alignment on Drivers

3. Owner's Planning Resources \& Processes

4. Timely Design Freeze

5. Early Completion Recognition

6. Preliminary Module Definition

7. Owner-Furnished/Long-Lead Equipment Specification

8. Cost Savings Recognition

9. Contractor Leadership

10. Contractor Experience
11. Module Fabricator Capability

12. Investment in Studies

13. Heavy Lift/Site Transport Capabilities

14. Vendor Involvement

15. Operations \& Maintenance Provisions

16. Transport Infrastructure

17. Owner Delay Avoidance

18. Data for Optimization

19. Continuity through Project Phases

20. Management of Execution Risks

21. Transport Delay Avoidance

Then, the researchers collected information from actual industrial modular projects through a survey and interview, measured the degree of accomplishment for each CSF across the entire sample, and compared the modularization CSF accomplishment degree between 25 actual sample projects (project based) and the industry experts' survey results (experience-based estimation).

The researchers contacted a total of 94 modular experts, and received information from 25 sample projects through a survey questionnaire sent out to 20 modular experts (response rate was $21.28 \%$, see Figure 1). The respondents were asked to provide information on their most recent modular project.

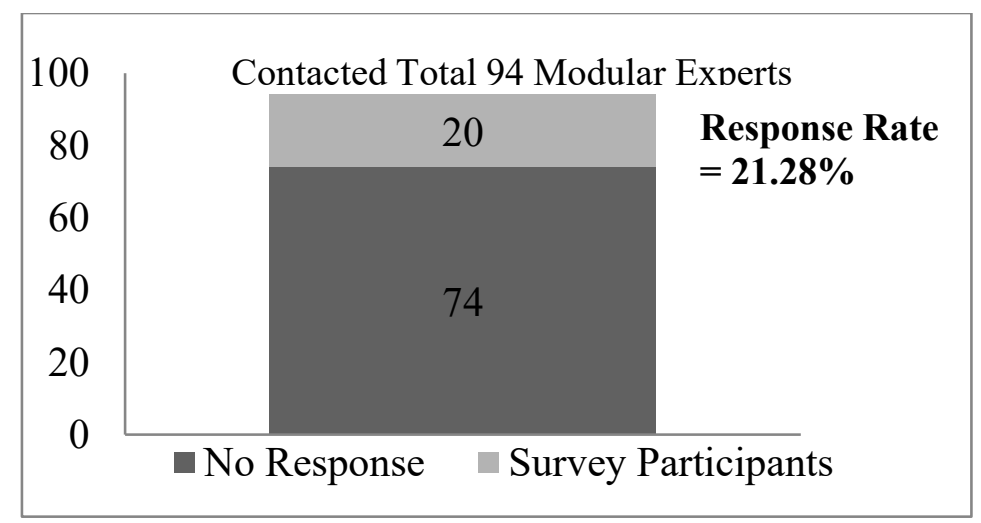

Figure 1. Number of Contacted Experts and Response Rate 
The source of collected sample projects can be grouped into four categories (Figure 2): 1) CII Modularization Community of Practices (MCOP); 2) Front-end-planning Community of Practices (FEPCOP); 3) CII Implementation Resource (IR) Publication Reviewers; and 4) Others.

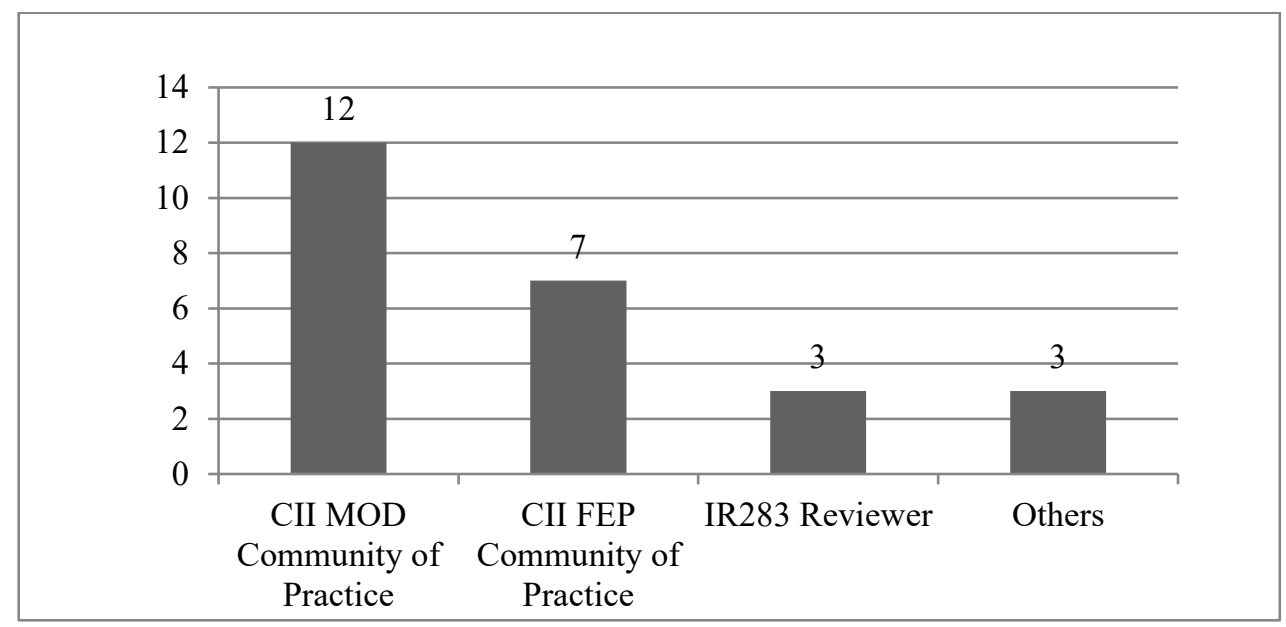

Figure 2. Number of Projects by Source Group

The median total installation cost (TIC) of the 25 sample projects was about $\$ 300$ million, and the median duration of the sample projects was 24 months. The types of projects (plants) included, but were not limited to, natural gas processing, consumer products manufacturing, oil producing, power producing, and chemical manufacturing.

The industry status of the modularization CSFs accomplishment was measured in terms of degree of accomplishment. The degree of CSF accomplishment was measured according to five levels: $\mathrm{N} / \mathrm{A}=$ not applicable/don't know; $0 \%=$ not accomplished; $30 \%=$ partially accomplished; $70 \%=$ mostly accomplished; and $100 \%=$ fully accomplished. The survey questions about CSF accomplishment were the close-ended type. Later, a descriptive research methodology was used to analyze the CSFs accomplishment statuses and compare CSFs accomplishment frequencies between the sample projects and CII RT 283 experts' survey results. To compare these two measurements on the same scale, normalization was conducted for the CII RT283's survey results.

\section{RESULTS}

\section{Comparison of CSF Accomplishment Degree between Sample Projects and CII RT 283}

Figure 3 illustrates a comparison analysis of CSF accomplishment degree between actual sample project accomplishment from the current study (actual project based) and the CII RT283's industry experts' survey results (experience based estimation). Relatively small variances in most of the CSFs were identified between the actual sample projects' accomplishments from the current study and the CII RT283's industry experts' survey results, as Figure 3 illustrates. This result indicates that the CII RT283's industry experts made good estimations of the current degree of occurrence of each CSF.

The study did identify, however, three significantly overestimated CSFs and three underestimated CSFs. The overestimated CSFs refer to those having a high RT283's survey result, but low actual accomplishment in the sample projects. The underestimated CSFs refer to the converse of such a 
situation. As mentioned earlier, this analysis was conducted through normalization to compare the two results. Hence, it highlighted only three significantly overestimated CSFs and three underestimated CSFs. This process was conducted by computing the variance (delta) amount between average variance (0.11) and that of each CSF.

The three most overestimated CSFs are:

- CSF7 Owner- Furnished/Long Lead Equipment Specification

- CSF8 Cost Savings Recognition

- CSF15 O\&M Provisions

The three most underestimated CSFs are:

- CSF10 Contractor Experience

- CSF20 Management Of Execution Risks

- CSF21 Transport Delay Avoidance

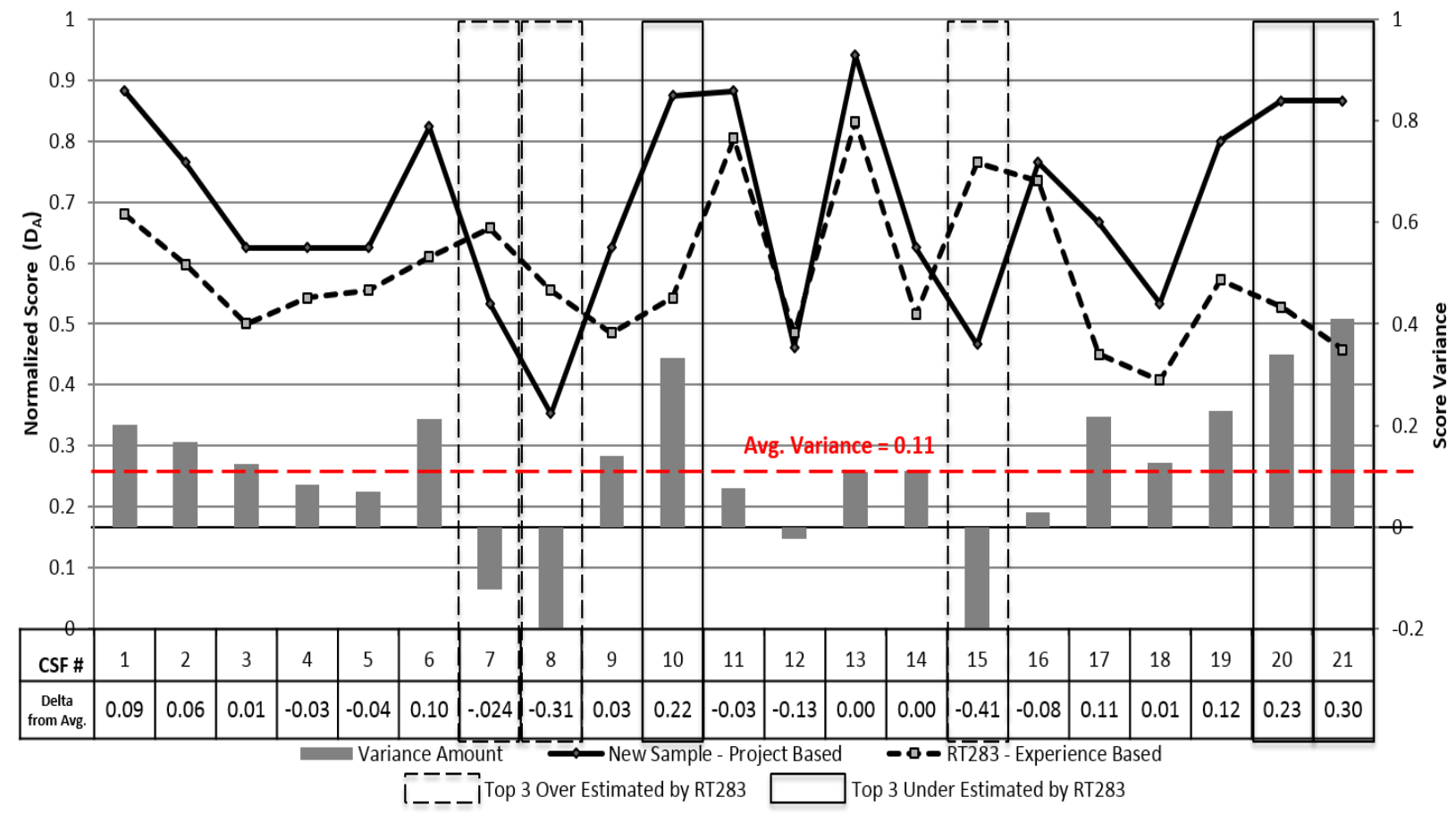

Figure 3. Comparison of CSFs Accomplishment Degree between Sample Projects and CII RT 283

\section{CONCLUSION}

This paper attempted to validate the CII RT283's accomplishment survey results by comparing them with the accomplishments found on the sample projects. The study results indicate that the industry experts made good estimations of the current occurrence degree of each CSF. The study did identify, however, three significantly overestimated CSFs and three underestimated CSFs. The three most overestimated CSFs are Owner-Furnished/Long Lead Equipment Specification, Cost 
Savings Recognition, and O\&M Provisions. The three most underestimated CSFs are Contractor Experience, Management of Execution Risks, and Transport Delay Avoidance.

The implication of this result is a recommendation of modification of the CII RT 283 findings on the accomplishment analysis that recommended the industry accomplishing the occasional, rare, and very rare CSFs, particularly for those with high impact rankings, such as Owner's Planning Resources \& Processes, and Contractor Leadership. According to the author's analysis, the industry needs to pay more attention to Owner- Furnished/Long Lead Equipment Specification and Cost Savings Recognition as those CSFs were under accomplished but can impact high. This study will help the industry to: 1) better understand modularization CSFs and their accomplishment status; 2) achieve higher modular project performance by accomplishing the CSFs.

As a next step, the researchers plan to submit a journal paper that presents the following items based on the in-depth analysis:

- Lowest CSFs in terms of degree of accomplishment among sample projects

- Highest CSFs in terms of degree of accomplishment among sample projects

- Timeliest CSFs in terms of accomplishment timing among sample projects

- Most delayed CSFs in terms of accomplishment timing

- Comparison of CSF accomplishment timing

\section{ACKNOWLEDGEMENTS}

This paper is based on Jin Ouk Choi's Ph.D. dissertation of the University of Texas at Austin (Choi 2014). The authors would like to thank all the people involved in this research and the experts who participated in the survey for sharing their time and expertise. Especially, the Construction Industry Institute Modularization Community of Business Advancement (CII MCBA) greatly supported this research.

\section{REFERENCES}

Alwisy, A., Bu Hamdan, S., Barkokebas, B., Bouferguene, A., \& Al-Hussein, M. (2018). A BIMbased automation of design and drafting for manufacturing of wood panels for modular residential buildings. International Journal of Construction Management, 1-19.

Azhar, S., Lukkad, M. Y., \& Ahmad, I. (2012, April). Modular v. stick-built construction: Identification of critical decision-making factors. In ASC Proceedings of the 48th Annual Conference.

Choi, J. O. (2014). "Links between Modularization Critical Success Factors and Project Performance." Ph.D. Dissertation, The University of Texas at Austin, Austin, TX.

Choi, J. O., Chen, X. B., \& Kim, T. W. (2017). Opportunities and challenges of modular methods in dense urban environment. International Journal of Construction Management, 1-13. doi:10.1080/15623599.2017.1382093

Choi, J. O., O’Connor, J. T., \& Kim, T. W. (2016). Recipes for cost and schedule successes in industrial modular projects: Qualitative comparative analysis. Journal of Construction Engineering and Management, 142(10), 04016055.

Construction Industry Institute (CII). (2012). Industrial Modularization: How to Optimize; How to Maximize. The University of Texas at Austin: Construction Industry Institute, Austin, TX. 
Hwang, B. G., Shan, M., \& Looi, K. Y. (2018). Key constraints and mitigation strategies for prefabricated prefinished volumetric construction. Journal of Cleaner Production, 183, 183193.

Li, L., Li, Z., Wu, G., \& Li, X. (2018). Critical Success Factors for Project Planning and Control in Prefabrication Housing Production: A China Study. Sustainability, 10(3), 836.

Molavi, J., \& Barral, D. L. (2016). A Construction Procurement Method to Achieve Sustainability in Modular Construction. Procardia Engineering, 145, 1362-1369.

O’Connor J. T., O’Brien W. J., Choi J. O. (2014). Critical success factors and enablers for optimum and maximum industrial modularization. J Constr Eng Manag, American Soc Civil Eng. 140(6):04014012.

O’Connor, J. T., O’Brien, W. J., and Choi, J. O. (2013). "Industrial modularization: How to optimize; How to maximize." Univ. of Texas, Construction Industry Institute, Austin, TX.

O’Connor, J. T., O’Brien, W. J., and Choi, J. O. (2015). "Standardization strategy for modular industrial plants.” J. Constr. Eng.Manage., 10.1061/ (ASCE)CO.1943-7862.0001001, 4015026.

Pan, W., Gibb, A. G., \& Dainty, A. R. (2007). Perspectives of UK housebuilders on the use of offsite modern methods of construction. Construction management and Economics, 25(2), 183-194.

Peltokorpi, A., Olivieri, H., Granja, A. D., \& Seppänen, O. (2018). Categorizing modularization strategies to achieve various objectives of building investments. Construction Management and Economics, 36(1), 32-48.

Salama, T., Salah, A., Moselhi, O., \& Al-Hussein, M. (2017). Near optimum selection of module configuration for efficient modular construction. Automation in Construction, 83, 316-329.

Sedaghat, N. (2016). A Conceptual Cost Comparison Study between Alberta and Overseas Module Assembly Strategies for Industrial Construction Projects (Master Thesis, University of Alberta).

Shahtaheri, Y., Rausch, C., West, J., Haas, C., \& Nahangi, M. (2017). Managing risk in modular construction using dimensional and geometric tolerance strategies. Automation in Construction, 83, 303-315.

Shi, Q., Zhu, J., \& Li, Q. (2018). Cooperative evolutionary game and applications in construction supplier tendency. Complexity, 2018.

Tatum, C. B., Vanegas, J. A., and Williams, J. M. (1987). —Constructability Improvement Using Prefabrication, Preassembly, and Modularization. Univ. of Texas, Construction Industry Institute, Austin, TX. 